\title{
Salutogenic Architecture
}

\author{
Jan A. Golembiewski
}

\section{Introduction}

Following many years of effort of Alan Dilani and the International Academy of Design and Health (Dilani, 2006, 2008), the term 'salutogenic' has made inroads to hospital design, and it is creeping into the architectural design of aged care, schools, workplaces and correctional care - at least at first as a buzzword for marketing. The term was coined to describe Antonovsky's model for socio-environmental influences on health. However, in most designers' hyperbole it means little more than fuzzy intentions to create restorative environments by providing views that represent nature: whether it be vegetation (designed parkland, grassy areas, trees, etc.), views of the sky or even photographic representations of these things. The theory is thus often bleached of its full potential, like an apothecary that only stocks aspirin. The architectural design industry can take a great deal more from salutogenic theory than it currently does.

But to do so, it needs to dig deeper into the theory to be better informed about how their ideas and interventions are likely to be helpful on a case-by-case basis, and perhaps more importantly, to reach beyond the axiom of 'views of nature' and locate other ways to use the environment to improve health outcomes - especially in conditions where views into natural woodland just are not possible, are inappropriate or simply insufficient. The marketer's sense that salutogenic theory is a powerful tool for determining design impacts on health is well-placed; as Antonovsky suggested, salutogenesis might be the only comprehensive theory of health promotion (1996), and it is certainly one that can be used in diverse disciplines as this handbook attests. In short, it is something the architectural industry needs for the design process itself, not just for marketing spin.

J. A. Golembiewski ( $\square)$

Psychological Design, Sydney, Australia

Interior Architecture and Environmental Design, Bilkent

University, Ankara, Turkey

e-mail: jg@psychological.design
This chapter is about how we can bring salutogenic theory to (literally) concrete reality using architectural design. The following sections look at salutogenesis as a model - comparing it with other models of health-oriented architecture, then it looks at salutogenesis in general terms before looking at how it can be applied by addressing each of the Specific Resistance Resources (SRRs - more about them later).

\section{Limitations of Previous Theories Linking Aesthetic Design and Health}

Substantial evidence shows aesthetic design interventions can affect health. Several theories have been offered to explain these effects - but most of them are limited to the specific interests of the theorists. Examples include an evolutionary hypothesis to explain the restorative effects of nature (The Biophilia Hypothesis (BH) of Wilson, 1984); the influence of 'views of nature' (The Stress Reduction Theory (SRT) of Ulrich, 1991); the very similar Attention Restoration Theory (ART) of Kaplan and Kaplan (1989); and the Ecological Theory (ET) of Lawton and Nahemow (1973), which argued that there is a 'sweet spot' to be found in a trade-off between designing for comfort and designing for mental and physical challenges. In addition to these, architectural and urban layouts have been found to indirectly affect a person's biology. For instance, natural light-filled structures will influence sunlight-dependent Vitamin D, serotonin, melatonin and L-Dopa levels (Deguchi \& Axelrod, 1972).

Of the bodies of research the designed environment on health, BH (Wilson, 1984), its architectural twin, SRT (Ulrich, 1991) and close relative, ART (Kaplan \& Kaplan, 1982), have been the pre-eminent models for translating design to health - largely because these theories have been subject to half a century of study, and also because the first scientific health + design studies drew on these 'low-hanging fruit' as a theoretical premise. ART, SRT and BH involve designing closer relationships with naturalistic elements like views into vegetation and the presence of pet animals. $\mathrm{BH}$ 
makes this explicit, whereas the ART acknowledges all 'fascinating' environments for the way they allow people to rest their cognitive processes. In effect the way these theories are translated into means that most health design research is not actually about designing better buildings, but turning away from the environments we build, and towards the ones we plant - or better still, totally natural environments. Again, the question is, are BH and ART sufficient to explain the salutogenic effects we see in bio-oriented designs?

The BH, SRT, ART, Medical and salutogenic approaches are not mutually exclusive, but any health benefits we see from ART, SRT or BH approaches are better understood using the salutogenic framework than from within their paradigms, or even using the Medical paradigm, because of all these models, only the salutogenic theory has broad enough scope to encompass them all.

\section{Overview of Salutogenic Theory and its Relevance to Architecture}

While these theories are all important, they ignore the elephant in the room - that architecture can be psychologically manipulative, for better or for worse. Architecture does this by providing a narrative context. It continually tells a story, which affects people's behaviour, how they are treated by others and how they feel about themselves. The story further influences neural and endocrine systems through the biochemical correlates of these emotions (Sapolsky, 2017). It is evident then that architecture can directly influence health (Golembiewski, 2016), but how can architects plan for these effects? Antonovsky's salutogenic theory provides an accessible overarching logic for determining the health and well-being benefits of design (Golembiewski, 2012b), beyond the basics covered by Environmental Medicine ${ }^{1,2}$ and without the need to understand any illnesses suffered by the environment's users. The theory does this by modelling how a person's milieu enables action in the ceaseless endeavour of the betterment of one's life and circumstances. The milieu is both social and physical - and this chapter is concerned by the latter. Does the environment enable physical actions? Does it provide clarity? Does it provide for emotional support? Or does the environment block action, frustrate plans and make people feel exasperated? These are the questions to be asked when assessing how 'salutogenic' a design is.

The salutogenic theory is not a model of disease, rather it is a model of health (Mittelmark \& Bull, 2013). As a theory,

\footnotetext{
${ }^{1}$ Environmental Medicine is a field of Public Health focusing on environmental toxicity and other specific risks to somatic health.

${ }^{2}$ Medicine, Medical and Health are capitalised to refer to the prevalent health paradigm, rather than to individual treatments, endpoints and goals.
}

it has a scope and perspective that other ways of understanding health lack (Antonovsky, 1996), yet it is not an alternative to Medicine ${ }^{3}$ or Public Health interventions. Salutogenesis looks the opposite direction, towards a more vibrant sense of well-being; towards better and more robust health; healthpromotion and recovery-orientation, rather than to the illnesses that threaten life. But salutogenesis is not the opposite of orthodox Medicine, rather it is complementary, in the true sense of the word. Because they are health-oriented, salutogenic interventions are largely general in nature and are therefore best used to support common-sense health initiatives. Salutogenic interventions work because they inform systems and environments design to speed the natural process of recovery, provide insight into social approaches to complex health problems and promote health before disease or infirmity ever takes hold. But this does not mean they are not powerful - a strong salutogenic disposition may mean survival against impossible odds, as witnessed by Frankl (1963), a psychiatrist and prisoner in the concentration camps of World War II.

Salutogenesis is a way of understanding the entire spectrum of wellness and illness, regardless of specificity and detail. The salutogenic theory does not only seek to improve health but to assist in all other human endeavours because that is the level on which it works. Thus, salutogenic interventions do not make people better, they make architectural and other interventions better, and in that way, salutogenic interventions help people to help themselves, to get the most out of their lives and to be their best selves. Salutogenic approaches, therefore, reach beyond Medicine, to maximise our endeavours, help us fulfil our desires and provide for our constantly evolving needs to improve our circumstances. This broad effort is understood as the basis for maintaining and supporting one's health (Golembiewski, 2013b).

Salutogenic theory explains how generalised factors affect well-being wherever we find ourselves on the health/illness spectra. As such, it is useful for managing indirect, complex, obscure or unknown factors of health such as our general motivations and frailties, including those that lead us to fall prone to illness. ${ }^{4}$ Because salutogenic theory has this higherlevel validity, it continues to make sense beyond the specific findings of experiments and singular design interventions (Strümpfer et al., 1998a, 1998b). Salutogenic theory provides a basis for informed decision making in the absence of specific knowledge or whenever circumstances are too complex to suggest easy solutions, such as design choices that must be made now for an unknown future. In short, salutogenesis is an excellent model to provide insight and inspire health professionals

\footnotetext{
${ }^{3}$ Antonovsky makes it clear that Salutogenic Theory does not advocate abandoning Medicine (1987, p.13).

${ }^{4}$ This kind of complexity typifies the way the physical environment affects health.
} 
to provide intangible help in addition to just prescriptive treatments, and for non-health professionals (like architects and urban designers), Salutogenic theory helps recognise that they too can bring a health dimension to their work just by making spaces and places easier to negotiate and more human.

\section{Relationships Between General Resistance Resources and Stressors}

The theory of salutogenesis asserts that good social/emotional, psychological, and physical/somatic health is maintained through a dynamic ability to adapt to life's changing circumstances. The opposite is also true - challenges that are too great to overcome or adapt to exert an aetiological influence on illness. One 'succumbs to illness', when demands exceed one's capacity to cope with them (Antonovsky, 1972), that is when the salutogenic resources are not sufficient to support ones' needs and desires in the face of adversity and challenges. So, a germ on its own is insufficient to cause a disease - it needs to be cultured in an environment that lacks the capacity for resistance. Models that accept 'multiple causation' typically describe the specific influences that cause maladaptivity as 'stressors': but these must include everything from intensely joyous events to life's tragedies and banal concerns (Antonovsky, 1987). In effect, everything can be considered a stressor unless there is a model that can predict which stressors will cause failure and which will be successfully negotiated - or even be celebrated. The 'stress' concept, as it is widely accepted, is therefore useless except in post hoc reflection. The forces at work to improve adaptability, on the other hand, are specific enough to allow practical, buildable and highly bespoke solutions.

When applying salutogenesis to architecture, it is a useful conceit to picture GRRs and GRDs as opposing forces in a zero-sum equation. On the one hand, the combined support (the generalised resistance resources or GRRs) stack up (and must be stronger than) life's challenges, whatever they may be, which we can also imagine as deleterious forces (the generalised resistance deficits or GRDs ${ }^{5}$ ). Where GRRs are stronger, a person will be left with a robust, flexible and buoyant sense of coherence (SOC), which will maximise ones' resistance to illness, or (at the least) enable a prompt and full recovery. Where GRRs are low, adaptive failures will occur, and these lead to decline and even death.

\footnotetext{
${ }^{5}$ GRDs are not actually forces, much less deleterious ones called 'stressors' in most health promotion literature. Antonovsky observes that 'stressors' are 'omnipresent, ...not necessarily pathological and may be salutary' in some instances (1987, p.12). They tend to be random and agnostic. The only danger is that there are absences of the resources needed to deal with them. The desert sun is an example. If you have photovoltaic panels, the same energy that can so easily kill can equally supply valuable power.
}

The GRRs fall into three domains, each of which relates to one of the dimensions in Antonovsky's description of the SOC in his 1987 book: ' ...the extent to which one has a pervasive, enduring though dynamic feeling of confidence that;

1. ... one's environments... are structured, predictable and explicable;

2. The resources are available to meet ... demands...; and

3. These demands are challenges, worthy of investment and engagement' (pp. 18-19).

The GRRs then, are those resources that enhance the cognitive domain - comprehensibility [1]; those that enhance the domain of action and physical resources - manageability [2]; and those that enhance the affective domain - meaningfulness [3]. The adverse forces, on the other hand, are any challenges to the resistance resources. In salutogenic theory, these are usually lumped together because they are ubiquitous, arising as they do from natural entropy and the relentless inevitability of eventual death. And much as we like to personify these negative forces as vindictive and aggressive, at least in his later work (1987 onwards), Antonovsky sees the GRDs simply as insufficiencies; as deficits that exert a continuous disintegrative force, allowing illnesses to overcome a person when the GRRs are too weak to support a robust and dynamic SOC (Antonovsky, 1996). But on occasion, the resource deficits can be very specific and vulnerable to specific antagonists, in which case the deficits are called the SRDs (the specific resource deficits) (Mittelmark et al., 2017). Scurvy, for instance, is caused by a lack of vitamin C. In this instance, no alternative resource will suffice. But at this level of specificity, the SRRs are inseparable from the treatments and preventions that fuel the Medical paradigm, so an important point can be made here: salutogenic interventions can be as specific as any medical intervention to address specific resistance deficits but are usually very generalised to fortify a person holistically.

When one is unable to adapt to circumstances and experiences, people cannot manage even the simplest tasks. This causes a 'breakdown' (Antonovsky, 1972: 64), and illness follows shortly thereafter. But with knowledge of the GRR/GRD (SRR/SRD) dynamics, a scaffold emerges that can be readily applied to tailor resources for just about all endeavours - including architectural and urban design. SOCsupportive design can help liberate the other GRRs to work together to enable resistance to disease and reduce the disintegrative forces that cause maladaptation in the first instance.

A useful way to illustrate salutogenesis is through metaphor (Fig. 26.1). A person regards adversity and challenges much as a knight who goes out daily to slay dragons. The knight finds meaning in fighting dragons (the meaningfulness salutogenic resource) - in protecting the society she loves so much, in the ribbon from her beaux that is tied to 
Fig. 26.1 A useful way to understand salutogenesis is through metaphor.

(Illustration courtesy of the author by J Golembiewski)

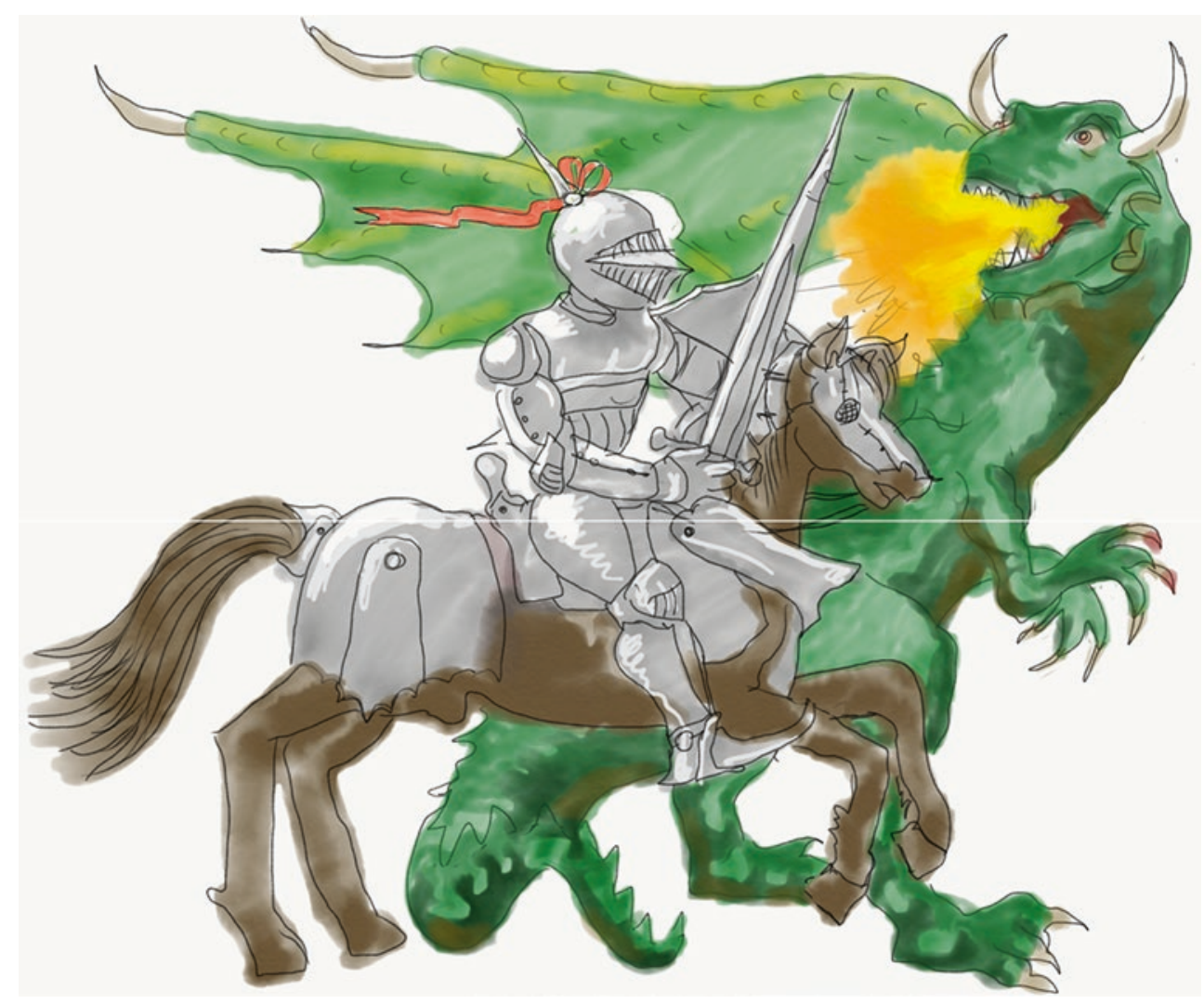

her helmet, in the heroism of her actions. But the knight also needs to act, and protection and tools to do so: it is in her armour, shield and sword the knight finds her manageability resources. Finally, she also needs knowledge. The knight needs to know how dragons move and attack; she needs tactics, plans and skills - and knowledge about how to communicate to her horse. Here the knight finds comprehensibility resources. These resources are the specific resistance resources (SRRs) - collectively known as the generalised resistance resources (GRRs). Deficits in any of these resources (generalised resistance deficits - GRDs) are dangerous and potentially fatal - holes in her armour, insufficient knowledge about dragons, and most critically, a lack of desire to fight them in the first place, lead to severe losses and possibly even death. Success on the battlefield, on the other hand, is rewarded by life - the knight returns triumphant, to a hero's welcome. The overall feeling the knight has, that she will ultimately either fail or triumph, is called the sense of coherence (SOC). A strong SOC improves the chances of success and makes health more robust. A weak one makes the night more vulnerable to any surprise turns from the dragons. The dragon metaphor distinguishes between GRDs and stressors: the dragon is just as much a malign force as it is essential to the SOC of the knight. Without the dragon, the knight cannot battle and return victorious. The SOC then is dependent on both adversity and the capacity to resist it.

\section{The Three SOC-Related Categories of Generalised Resistance Resources}

'Comprehensibility' resources are those of the cognitive domain. These help to make sense of one's life narrative, one's context and current circumstances, and without this fundamental knowledge and associated skills, people have little capacity to make the most of life's circumstances or to negotiate its challenges (Golembiewski, 2012c). In essence, comprehensibility is a person's sense of 'agency'. The ability to negotiate most of circumstance is an essential resource; people feel terrible frustration when they just cannot get what they want because they do not know how or other reasons. Because of the dissonance a failure of comprehensibility might cause, an extreme failure is often patched with an untested or improvised epistemic scaffolding, precipitating delusional ideas and magical thinking (Keinan, 1994), the worst of which might present as symptoms or predictors of paranoia (Antonovsky, 1987) or even psychosis (Mason et al., 2004).

'Manageability' resources are of the domain of action and are thus about physical resources and real actions. These are personified by the words, 'I $d o$.' Manageability resources are those a person needs to act. Mostly this activity relates to day-to-day physical realities like staying warm, dry, clean, rested, nourished and other the maintenance requirements of their physical lives. Many manageability actions involve 
critical processes such as cooking, cleaning and working. There is little question that these are basic concerns of architecture. But over the last few decades, concern for users' manageability has shifted to be more inclusive - to consider the needs of people with generic disabilities. Now manageability resources in architecture include requirements for universal accessibility - reachability, controllability, liveability comfort and staying safe - even for people who are deaf, blind or use wheelchairs.

In architecture, there is also a current trend to advance accessibility to the realm of inclusive design. Where universal accessibility aims to make the environment generically barrier-free for everyone but ends up making it easier for many users (with such things as the implementation of ramps for wheelchairs, strollers and skateboards), inclusive design attempts to solve accessibility problems for specific extreme cases, with the understanding that the solution will have side benefits for everyone (Clarkson et al., 2003) - for example, a designer might look at how buildings are used by people born with amelia (missing limbs). The architect might specify sound- or movement-activated light switches, which will provide the general benefits of making switches more sanitary and potentially even invisible. As advanced as it is, inclusive design is still largely concerned with enabling action and is, therefore, an approach to improve the manageability of architecture.

Manageability is mostly about doing things. And for the best part, this involves looking after one's self and others in your care. Failure to manage these tasks exemplify the traditional pathogenic definition of stress (Sapolsky, 2004), and total failure can easily lead to death.

'Meaningfulness': according to Antonovsky (1979) and Frankl (1963), meaningfulness is the principal reason for life. Meaningfulness resources are those of the emotional ('affective') domain. Meaningfulness provides the will to resist adversity, challenges, the entropic pull of illness and fears about death's inevitability. As such, it is (in so many ways) the most important of the salutogenic resources. Meaningfulness is also the most elusive because it is difficult to define and is intrinsically personal.

Meaningfulness is found in the intensity of personal connections, responsibilities and desires with the outside world: 'Profound ties to concrete, immediate others... and between an individual and his community are decisive resistance resources' (Antonovsky, 1972, p. 542). People find meaning in different social groupings, in different causes and concerns, and continually disagree wholeheartedly about how such concerns should be prioritised. Yet it is in these distinctions that people find the basis of a sense of identity and purpose (Frankl, 1963; Searles, 1966). Without meaningfulness, people find themselves utterly bereft of any desire to act and subsequently fall prey to somatic or mental illness (particularly the depressive signs and anhedonia) (Frankl, 1963; Searles, 1960, 1966), both of which can be fatal.

\section{Aesthetics of the Built Environment Influencing Health}

Salutogenesis is expressed in architecture through affordances - the opportunities that are structured into the environment that stimulate action; cause us to reflect on how we feel; or stimulate thought. Some of these affordances are aesthetic. They are thus 'regarded' as sensory information, rather than as things that directly manipulate us or vice versa. But this is a mistake. The idea that aesthetic concerns have an impact on health can be challenging because it could mean that where we thought about aesthetic decisions as ultimately empty opinions, these could prove to be therepeutic or deleterious.

For millennia humans have customised their accommodation as a resource to protect against danger, discomfort, wildlife, social threats and the deleterious effects of weather. Architecture's role in these protective purposes is fundamental. However, the supportive effect of architecture is not only physical but psychological too - if people cannot find respite from the pressures of life at home, the resulting compounding mental and emotional strain may be enough to cause debilitating mental illness, possibly even without an underlying biological or genetic dysfunction (Golembiewski, 2013a). But all shelter is not equal: even once we have achieved the basic need for shelter from the weather, the wild and other dangers, we continue to customise the environment on an aesthetic level (Fig. 26.2), in what appears to be an attempt to make the environment better on a psychological level. People have decorated their surroundings in all parts of the world since at least Neolithic times. Much of this effort is thought to be to create a sense of meaning and perhaps even to entreat gods to moderate circumstances that are otherwise beyond human control (Harari, 2015).

Perhaps because of these ancient origins, the correlation of aesthetics and health (and even on mortality) appears to be superstitious and occult and is thus not nearly as widely accepted as evidence suggests it should (Golembiewski, 2016). But the impact of aesthetics (such things as views and presence of potted plants) on health has been scientifically tested thousands of times, including dozens of studies against a null hypothesis (a statistical method used to demonstrate causality). In 2005, a systematic review located and analysed 30 peer-reviewed articles that showed this effect to be significant and reliable (Dijkstra et al., 2006), with findings that sometimes defy belief - for example, $30.8 \%$ faster recovery and $38 \%$ lower mortality were found when patients recovering in hospital were given sunlit rooms for psychiatric 
Fig. 26.2 A 1400-year-old prayer niche in a cave in Göreme (Turkey) has been painstakingly carved and painted for apparently no functional purpose except to improve the space on a psychological level. (J. Golembiewski, Photograph courtesy of the author)

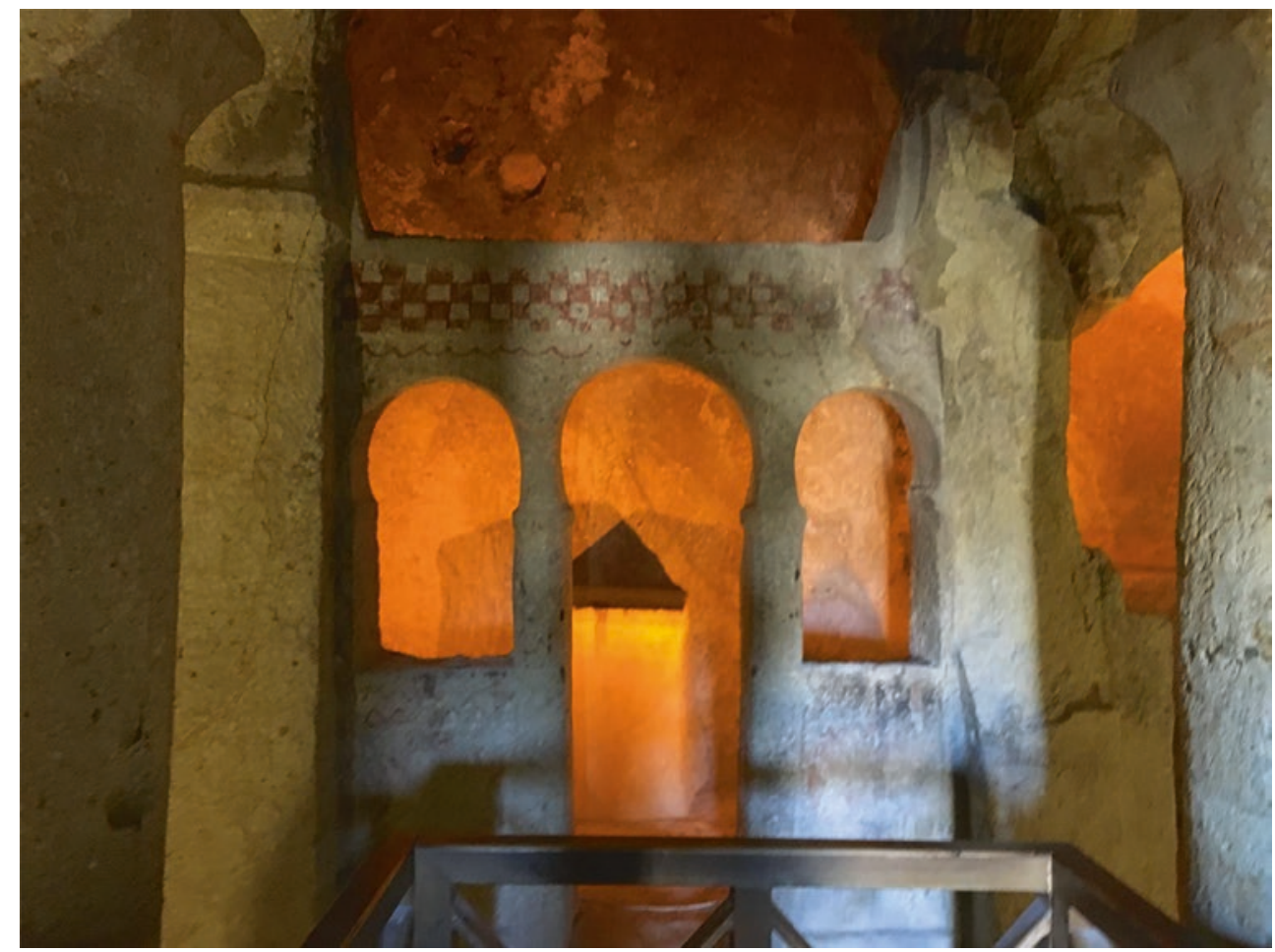

disorders (Beauchemin \& Hays, 1996, 1998) (an effect size that cannot be reasonably traced to vitamin D deficiencies!)

From a salutogenic perspective, such findings are of immense importance: when people are healthy, they demonstrate a theoretical surplus of resistance resources, so for many people, aesthetic improvements are nice, but are not essential, unless they seek extraordinary levels of wellness. Maslow (1962) described these people as 'peakers' - the highly creative souls who maximise the human experience and thrive in a state of self-actualisation. These people have an insatiable desire for the greater states of well-being. But many people are not concerned for peak experience and are happy to get on being simply 'well' (Maslow, 1962) This means that many people who do not currently suffer from disease can too easily dismiss the impact of aesthetics. But when people are ill, they suffer in the balance between deterioration and recovery, so any genuine influences (whether for better or worse) are likely to reflect in their SOC, and because of that, their ability to recover. As an example, two cohorts of severe psychiatric patients (each $n=10$ ) and 10 matched healthy controls were shown emotionally manipulative imagery whilst undergoing fMRI of their frontal lobes. When the observed inhibitory potential was subtracted from the activation caused by the images, the differences between the cohorts were extreme - especially when it came to negative images, where the psychiatric patients showed greater surplus excitation than the controls. The implication is that the healthy controls had the resources they required to process the negative images fully, and therefore barely noticed and change. Whereas the psychiatric patients did not have the resources to reprocess this information. The surplus triggered symptoms, therefore adding to the diagnosable criteria of disease, thereby making the patients only sicker (Golembiewski, 2012a).

When Antonovsky speaks of the outside world, he uses the term 'stimulus' to refer to the neurological effect the environment evokes (as observed in scientific studies like the one just mentioned). This way of referring to the environment typifies scientific attitudes, but the term denigrates the omnipresent and immersive quality of the environment, which is as fundamental to existence as the three dimensions of SOC. Certainly, the environment is replete with stimuli, but it is so much more than that because our bodies, minds and emotions simply cannot exist without context. The built environment is full of opportunities and restrictions - aesthetic ones (as above) and physical ones like fences and walls, and opportunities like pathways, bridges or windows. All of these determine the choices we make. Some are insignificant - for example, there is little phenomenological difference between a left or right turn, even though they are opposites. But many physical restrictions and opportunities are deliberately there to moderate our behaviour (Golembiewski, 2016). Consider the design of shops, for instance, where every detail is assessed on its capacity to improve sales (Turley \& Milliman, 2000). The manipulative possibilities of the physical environment can be used to directly improve 'factors' which are thought to affect health outcomes also: cities around the world are compiling 'fit 
city' design guidelines to encourage people to take the stairs and leave the car behind, and walk or cycle instead (City of New York, 2013; Jackson \& Sinclair, 2012). Physical interventions like these are often assumed to be the most the built environment can do to improve health - if only because the therapeutic pathways between aesthetics and health outcomes are difficult to trace or predict. This is of course where salutogenesis is most useful. Salutogenesis groups supportive factors (GRRs, SRRs), and deficits (GRDs, SRDs), and when deficits outweigh resistance resources, people will fall sick in the way they are genetically, physiologically, biologically, mentally and socially most vulnerable.

When designing at an urban scale, models like the "fit city' initiatives make axiomatic sense - with greater fitness, comes better health. And people mistakenly believe this to be the basis for the salutogenic effect (e.g. Mazuch, 2017). Although there is a relationship, it is not only because of increased fitness levels of residents. It is more because the 'fit city' architecture provides good things to do, positive choices and pleasant experiences, including exposure to urban green spaces, all of which support resistance resources. The 'fit city' choices have a broad psychological benefit to the whole community that far outweighs the physical fitness benefit that is conferred only to a few individuals. Perhaps the greatest generalised benefit is from having choices. The possibility of something healthy to do provides everyone with a sense of meaningfulness, regardless of whether the affordance is accepted and acted on. Of the impressive results reviewed by Dijkstra et al. (2006), none of the health improvements of persons in healthcare institutions was because the hospitals had more steps or longer corridors. Most salutogenic factors of causation are not directly somatic, but aesthetic - they are largely psychological rather than physical.

\section{Promoting Manageability, Comprehensibility and Meaningfulness in Architecture}

As pointed out early in this chapter, the traditional lens for understanding the impact of the built environment on health is focused on how well it provides basic functionality, shelter and whether it exposes users to toxins. The built environment is thus relevant to Medicine only in as much as it provides shelter, ease of cleaning and other basic functionality. This understanding has been somewhat updated to include views of nature to improve Medical outcomes, but still, it is a low bar. However, salutogenic architecture is not Medicine oriented; it is geared to support peoples' lives by helping them to cope with whatever life throws at them. It helps with manageability, comprehensibility and meaningfulness, and their collective synthesis: the sense of coherence (SOC). In other words, salutogenesis is a way of understanding the diverse ways a person can be helped through the natural process of recovery and development of positive health.

\section{Manageability in Architecture}

Perhaps one of the most obvious tests of the quality of architecture is manageability. Architecture is after all, the domain of the physical and tangible actions - and the built environment is nothing if not present in concrete reality. To understand what manageability is in architectural terms, we can look at the misery and impotence we feel when it is absent: the powerlessness we have when we cannot stop the weather (be it cold and penetrating rain, wind and snow or the opposite; unchecked heat and humidity) getting to us when we need something else - such as sleep or an environment where we can work. Poor design for manageability might be apparent in a building that requires you to bend over to reach things if you have arthritis, or again a chic home with white surfaces that never look or feel clean despite hours of effort.

In architecture, manageability resources are improved by:

- Functionality, 'fit-for-purpose' design

- Safety by design

- Barrier-free accessibility and design to enable action

- Person-centred design

- The design of positive affordances

- Forgiving design

Regarding functionality and fit-for-purpose design, the question is: does the design of your home/ workplace/school/ city/institutions enable you to do whatever it is that needs to be done or is the environment just a hindrance? Do not assume that the law or the good sense of architects have pre-empted these things for you. Do not expect that architects will ensure that a new home (which is surely a place to let go and relax) will be designed for that, and therefore fit-for-purpose. The responsibility for designing a building that actively fosters well-being can only be enforced by specific agreements to address this issue because fit-for-purpose design (bizarrely) is not considered a reasonable expectation of an architect (Cooke, 2001) - even if they are commissioned to design a family home, a school or hospital. On the other hand, that the design is physically safe is legally enforceable (and has been since the laws of Hammurabi of Babylon in 1792 BCE), and so too are specific access and egress provisions, especially for emergencies. But when armed with salutogenic theory to provide insight, manageability in architecture can mean so much more than just protection from the elements, safety and accessibility.

When talking about accessibility and enabling action, thoughtful consideration needs to be given to functionality and to the needs of anticipated users of the space over time. 
The way salutogenesis looks to peoples' needs, and not only to the needs of any illness they may suffer ('the person needs care' vs 'the wound needs dressing'), makes the salutogenic paradigm intrinsically person-centred. Person-centred (and its industry-specific equivalents: patient-centred for healthcare; student-centred for education; customer-centred for retail, etc.) design pays attention to the details that make living life easier: door-handles that are easily manipulated and will not stress weak or arthritic limbs; a well-defined and distinctive front door for someone with Alzheimer's disease; low-contrast, low reflectivity interiors for ageing eyes, lecture halls that do not draw attention to late students, etc. Some features are more universal: Why design shelves above $150 \mathrm{~cm}\left(5^{\prime}\right)$ for children, short males, most females or people who will one day grow old or might suffer a permanent or temporary disability?

These considerations improve the scope of manageability in design hugely. But manageability can be richer still. The most valuable tool designers can employ is positive affordance design. As mentioned earlier, we live an immersive experience of the world, and have an ecological relationship to it: the environment is not just 'stimulus'. We perceive the world around us through opportunities to act rather than through a rational cognitive process (Bargh, 1994; Gibson, 1979). These opportunities are called affordances. Mostly we sense affordances unconsciously. We walk down paths without thinking; 'Hey, how cool is it that this path is here, that it leads to where I want to go, and that the ground is stable and there's no poison ivy...' And yet we create paths like these all the time, and without them, we make entirely different choices. We sense affordances of all kinds - objects that inspire action, signs that tell us to do things and the calming aesthetic impacts of the natural environment (now there's where ART fits in!) (Golembiewski, 2013b). We are constantly presented with affordances, but the choice about whether to accept or deny the affordance is far more subject to our mood and outlook than most people can imagine. When we are feeling down or are ill, we are far less likely to notice positive things and far more likely to perceive negative ones (Golembiewski, 2012a). We are therefore more susceptible to make bad choices - that is, we are more likely to reject good choices and pick up on negative affordances than when we are healthy, happy and thriving (Golembiewski, 2014). But even when we are gloomy and in a space where we reject the best the world has to offer, having those good affordances present is nevertheless critical because the choice alone can make us feel better, whether we accept them or not.

Forgiving design improves manageability - a home that is designed to look great, even when it is a mess (Fig. 26.3); a building that is optimally positioned and ventilated to feel comfortable, even when the heating and air-conditioning are turned off (Brager \& de Dear, 1998) (Fig. 26.4); an urban layout that is of a human scale, which enables you to walk to your destination (Zook \& Ewing, 2010) (Fig. 26.5). All these affordances improve manageability.

Manageability is good and more manageability is better, but sometimes people find that decisions that are made to improve manageability can block the development of
Fig. 26.3 A home that is designed to look good, even when it is a mess.

(J. Golembiewski, Photograph courtesy of the author)

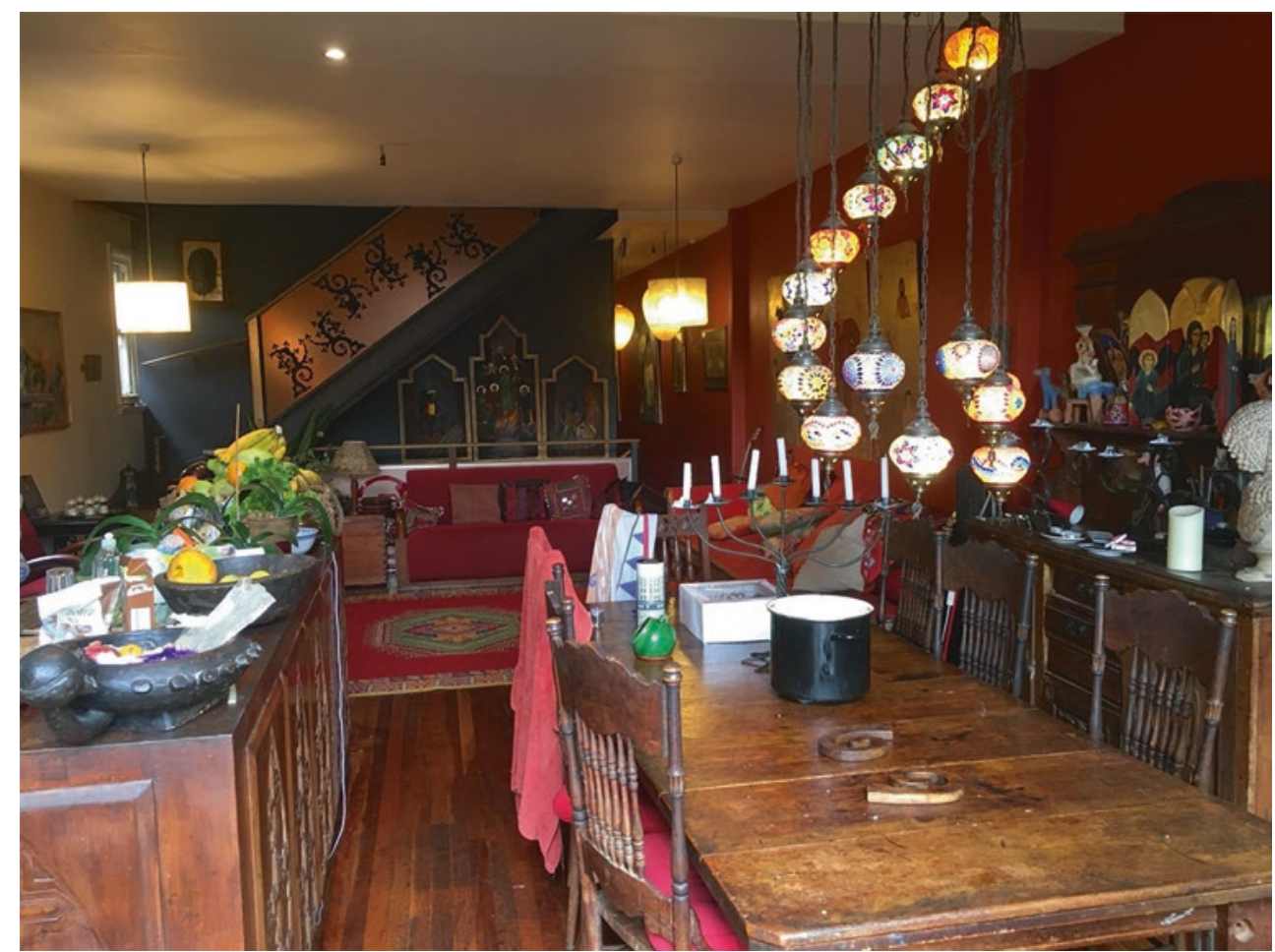


Fig. 26.4 A building that is optimally positioned and ventilated to feel comfortable, even when the heating and air-conditioning is turned off. courtesy of the author) (J. Golembiewski, Diagram
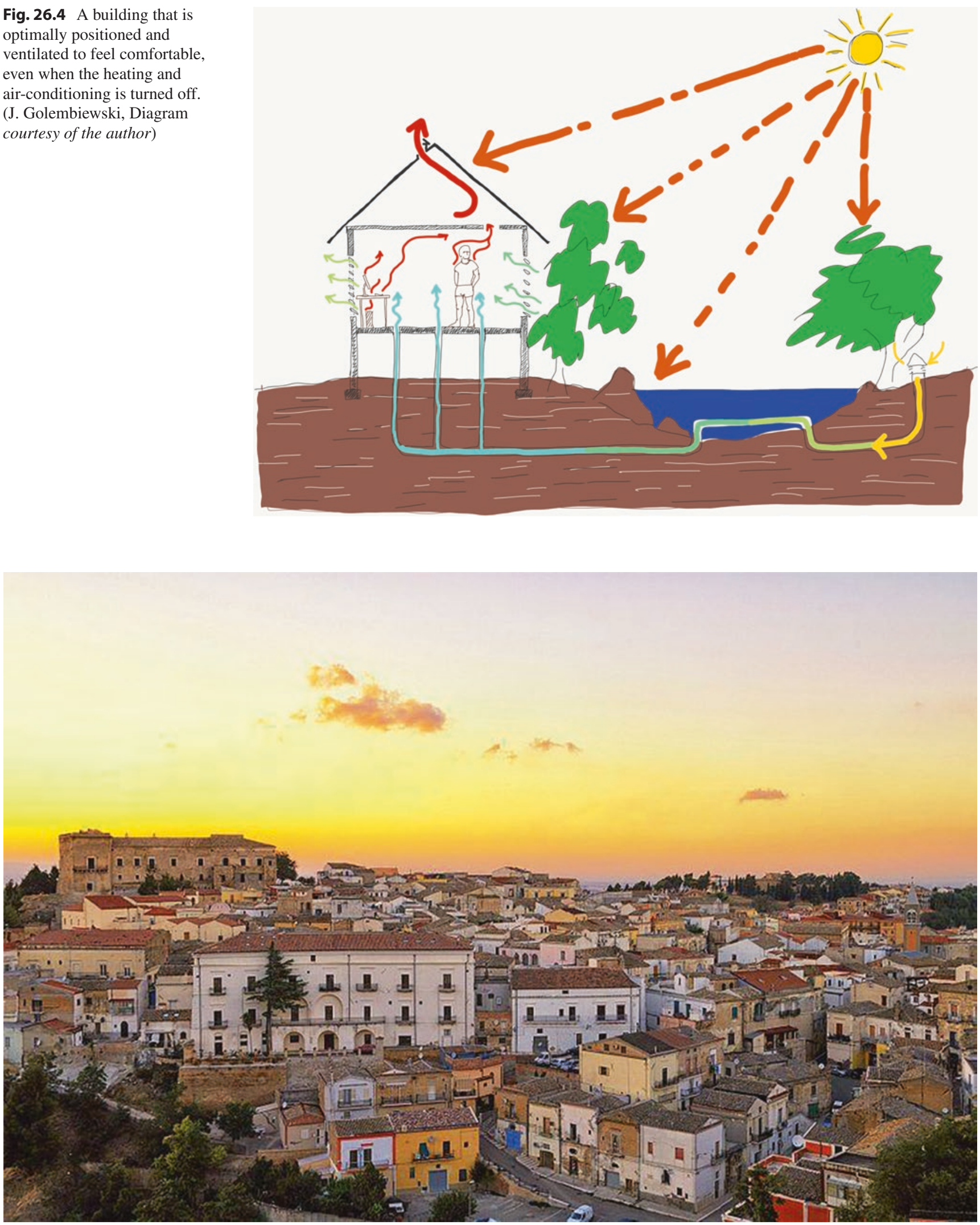

Fig. 26.5 An urban layout that is of a human scale, which enables you to walk to your destination - such cities are common in Europe. (Photograph of Ascoli Satriano courtesy of Giuseppe Valvano, under a CC Share-alike licence) 
Fig. 26.6 During the Jewish festival of Sukkot, people sleep rough outdoors in improvised shacks to deny comforts for greater spiritual gains. (Photograph courtesy of ציון הלוי, under a CC Share-alike licence)

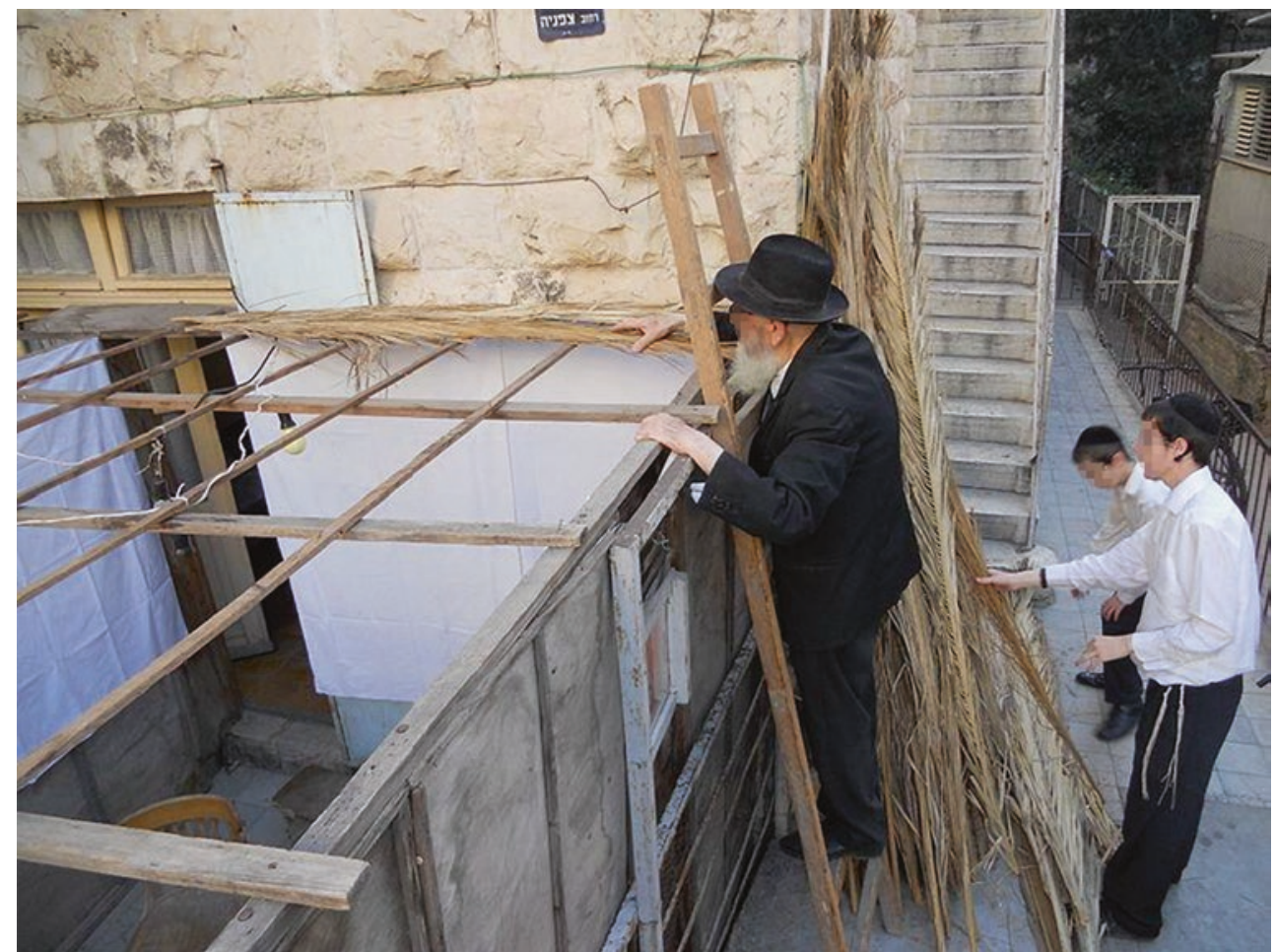

other more subtle salutogenic resources related to comprehensibility or meaningfulness, and therefore manageability may occasionally need to be sacrificed for other outcomes. A good example is diet. Someone may diet to reduce their body weight and to improve their self-image. Dieting is a deliberate restriction of manageability to improve comprehensibility because comprehensibility is about mental states (like self-image). Dieting may also be religious and therefore to improve meaningfulness. How this may apply to architecture is less obvious, but perhaps people may accept a smaller home to reduce their carbon-footprint or give part of their home over to others? There is a religious practice called Sukkah on the Jewish festival of Sukkot, where people sleep in a shack outside so they can feel the frailty of existence and acknowledge their dependence on the divine (Rubenstein, 1994) (Fig. 26.6). This is an architectural sacrifice of manageability for greater meaningfulness, although it is only temporary.

\section{Comprehensibility in Architecture}

Comprehensibility is the domain of the mind. It is 'the extent to which... the internal and external environments [make] cognitive sense... are orderable and explicable' (Antonovsky, 1987, pp. 16-17). An understanding of the rules, laws and the limits of the circumstances we find ourselves in gives us a foundation for improvement, should we wish to nego- tiate changes for our betterment. Comprehensibility, as it applies to the built environment, is therefore about a sense of agency: our capacity to understand, negotiate and customise the contexts we find ourselves in. It is about having the knowledge we need to get what we want out of life and to progress with certainty. Comprehensibility is structured into design through the following design values: readability, simplicity and predictability.

Of all these values, predictability is the most important. The brain is wired to feel uncomfortable with uncertainty, in a parallel way that the body is wired to react against hunger. If uncertainty is prolonged or significant, it will trigger the amygdalae, causing a fight/flight response, which in turn blocks frontal processes (which relate mostly to meaningfulness), the normal hormone and endocrine cycle is virtually abandoned while the brain secretes adrenocorticotropic hormones, glucocorticoids and beta-endorphin instead. This is good news if you are being chased by a bear because your blood pressure will increase to feed your muscles while you bolt. It also means the blood is more likely to clot just in case the bear gets a little taste. Various relevant psychological effects are also observed, including increased fear and paranoia. But unless you are genuinely being chased by a carnivore, these responses are more likely to kill you than uncertainty (Sapolsky, 2017). A lack of comprehensibility makes us feel like we are in a Kafkaesque trap: uncertainty is exhausting, frustrating and can feel like it will never end - in other words, it carries such a significant cognitive cost, many 
people will make decisions that involve self-harm, rather than wait out uncertainty (Berns et al., 2006).

Predictability is enhanced in architecture and urban design by the other virtues - simplicity and readability. But the main risks to predictability in the built environment are not architectural (unless there is a risk of collapse), they are housing insecurity and unpredictability of a warm and welcome atmosphere. With unstable housing (bad rental agreements and risks of foreclosure) health (particularly Mental Health) outcomes are also at risk (Libman et al., 2012). The atmosphere in the city, at work or home, can also be subject to sudden change, especially in overcrowded situations where the actions of a few can radically affect the well-being of others (Ittelson, 1978), and the fear that this might happen can be more disruptive than the actions themselves (as demonstrated in the rat studies of Calhoun, 1952).

Simplicity aids a sense of predictability. It is the reason why Robert Browning's 'less is more' adage is so popular among architects (Browning, 1856- quoted by architect, Mies Van Der Rohe in 1947). Surprisingly, simplicity is not easy to achieve in architectural and urban design and is often the hallmark of experience. While simplicity is desirable because it carries a lower cognitive and somatic burden, it is also empowering because it renders the environment easily subservient to a person's needs. Wayfinding, for instance, is easy in a simple layout. In a simple layout, you can go from A to B without having to rely on signage or directions - the very typology, landmarks and locations of buildings, spaces or rooms will tell you their purpose. One can navigate a simple street layout or simple building layout easily, without frustration, getting lost or trying to remember tricky directions. Simple buildings are also flexible by nature. They lend themselves to customisation easily, which means they make good tools, helping people do whatever it is that needs doing, simply by getting out of their way.

Again, readability assists in way-finding. People should be able to tell from a distance what space, room or building is used for based purely on prior experience, memory or knowledge of familiar patterns (Albright, 2015). But we read more into our buildings than just purpose. We can also read the intentions that are embodied through design. We read the materials, the lighting and other details and make all kinds of assessments about who we are when we are in the space. 'Is the space for me or against me? Am I welcome here?' Architects and their clients should be certain that buildings are designed to give positive, generous and uplifting answers to questions like these.

The premise of inclusive design is that we should design for the minority who need special considerations, and the majority will benefit. For those people who suffer from confusion, hallucinations and paranoia, the importance of making sense of the environment cannot be underestimated (Woodbury
\& Woodbury, 1969). For this reason, it is important to provide familiar environments in all conditions where users are expected to relax, take respite and comfort (so that definitively excludes experiences which are designed to be extraordinary, such as rides in Disneyland). Familiarity will take on cultural hues, but familiar concepts, languages, objects, forms, materials, textures, typologies, emotions and expectations will all improve this sense provided that they are essentially regarded as positive (Golembiewski, 2010, 2013c). These things speak to authenticity in design, material choice and intent.

The authenticity of symbolism, intent and materiality speaks to the universal virtue of honesty, and again to predictability. On some level, honest design using natural materials, predictable typologies and other features of straight-forward design demands a reciprocal response from inhabitants and reflects on the behaviour of inhabitants also - as if the architecture calls us to ask, 'Is this place authentic, and does it demand an authentic response from me?' Although little formal research has been conducted to link this approach to health outcomes, this design property and its relationship with honesty and virtue has been long recognised by the Shakers of Maine, USA (Vincent, 2012).

\section{Meaningfulness in Architecture}

Constant action is required even to maintain homeostasis you must breathe, eat, find shelter and so much more. This is because life is entropic: do nothing and you will die. Life is always an uphill battle. Even with constant attention and care, one will always have struggles and demons to fight, and a degree of failure is inevitable. At a point, the ultimate failure is assured because life itself is fatal. Having sufficient physical abilities and resources (manageability) helps, as does knowledge (comprehensibility) - but why would anyone even bother, except for an innate sense that life itself is worth it? This picture is depressing because what is being described here is what causes depression: find someone with no sense of meaning and they will be a portrait of the most distressing symptoms mood disorders. They will feel anhedonia (emotional flatness), avolition (disinterest in action) and may even present with alogia (where people stop bothering complete thoughts, validate assumptions and make sense).

The missing ingredient is meaningfulness: the thing that not only makes life worth living but can even turn hopeless adversity into joy. It is meaningfulness, the motivational power that drives us 'to get out of bed in the morning'. With a strong sense of meaningfulness, the salutogenic resource of affect (emotion) provides the capacity to turn ones' attention away from the uncertainties, negatives and difficulties of life and instead to focus instead on positive desires and what is otherwise good and purposeful. 
Of all the salutogenic resources, meaningfulness is the most abstract. Indeed, the more abstract our concerns are, the more meaningful. Meaningfulness starts with concerns for 'the other' and expands into abstractions that are indistinguishable from fantasies; beliefs in non-physical entities, metaphysics and commitments to heroism that override any kind of logic (comprehensibility), our basic instincts for the preservation of life (manageability) and even our primal abhorrence of atrocities (Kruglanski et al., 2009) (Fig. 26.7). Meaningfulness is thus exemplified by heroic acts where concerns for the self are sacrificed for the greater good - the good, that is, of whatever it is that a person believes is worth living for. For most people, this means family and friends, the good of greater society, of culture, perhaps the wellbeing of the planet or ecosystem or even of metaphysical concerns built of myths, religious beliefs and quite possibly even delusions. (Why not? This level of abstraction is the zone of untethered imagination.) Against these haughty aspirations, the demands of the physical world (the domain of manageability) can all too easily sing like sirens, ready to dash the hero's boat on all-to-physical rocks: the demands that one focus on bills, leaks, dinner or sleep instead of ones' magnum opus.

The abstract nature of meaningfulness poses difficulties for architects who wish to foster it because architects are required to be concerned with concrete realities (literally). Where building materials, methods and compliance might preoccupy the architect, their clients' sense of meaningfulness is linked to symbolic and fleeting representations of personal narratives. In a sense, concrete concerns are for architects the equivalent of pathologies for Medicine. How and why should doctors focus on what patients' think

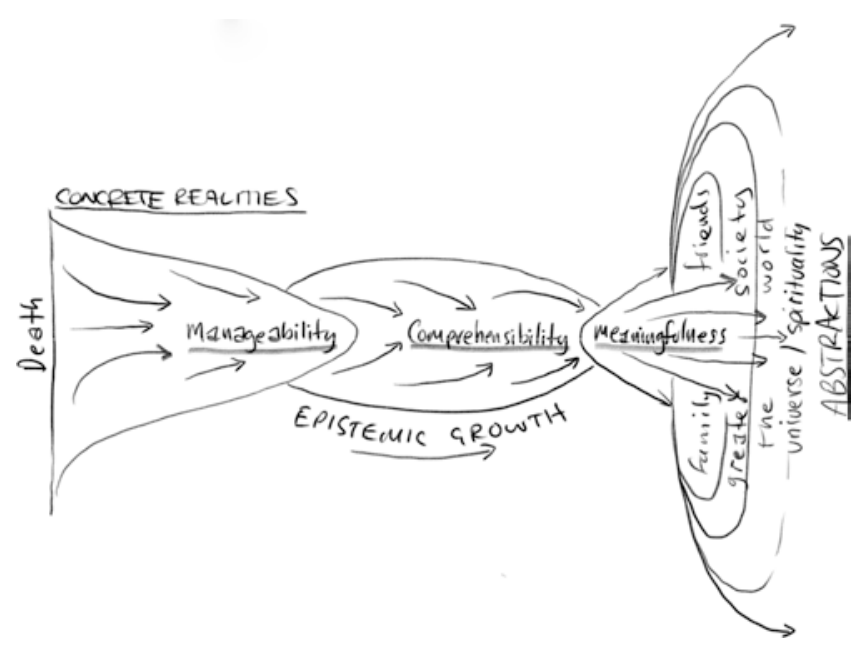

Fig. 26.7 Meaningfulness occurs most powerfully where concerns transcend self-interest and become more abstract - in connections, inspirations and metaphysical concerns. (Diagram J. Golembiewski, courtesy of the author) and believe when there is an infection to treat? But just as Medicine is well advised to turn around and take an expanded salutogenic perspective, so too is architecture.

In architecture, meaningfulness resources are improved by:

- Design for the greater good

- Setting the stage for positive narratives

(Often this means finding and eradicating meaninglessness-in-design)

- Embodying meaningful symbolic expressions

- Providing for meaningful engagement

- Design for positive choices

\section{Design for the Greater Good}

What is good and bad depends on perspective - but as the dragon metaphor illustrates, salutogenesis is a broad enough theory to allow for contradictions. It does not matter what 'good' is, provided people feel it. The greater good (as it is addressed by architecture) traditionally means designing buildings that are harmonious with their surroundings (the decorousness and eurythmy of Vitruvius). More recently the fashion for expressing common 'good' has been in environmentally sensitive and low-carbon-impact design or civicminded functionality.

\section{Setting the Stage for Positive Narratives}

Affect is processed using the limbic areas of the brain: the area of the brain that processes and deciphers narrative (Le Hunte \& Golembiewski, 2014). Emotions and narratives are neurologically interwoven. When we feel, it is because our endocrine chemistry changes in response to the narratives we experience. And for this reason, the most direct way to design for meaningfulness and to elicit positive emotions is to create architecture using the language of storytelling: to design as if buildings, precincts, rooms and other spaces were stage-sets. By asking "what does this "set" say to the user? And how does it deliver meaning?' architects can use the commonalities of language and culture to purposefully establish appropriate meaning. Similarly, the salutogenic architect can be surgical, addressing and designing for the SRDs that speak of undesirable narratives: the features of the built environment that say the wrong things and speak to meaninglessness as surely in real life as they do in a play: environments that are creepy or are difficult to negotiate are especially problematic - as are ones that use electronic surveillance, have disturbing acoustics, smells, textures or lighting in buildings and car-centric wastelands and dead-ends in urban design. 


\section{Embodying Meaningful Symbolic Expressions}

Architectural stage sets can be designed with universal or near-universal symbols of the greater good, such as hope, growth and attainment. These symbols should be implicit, rather than applied. (A prison-like environment with the words 'hope, freedom and safety' emblazoned on the walls by an interior designer (it happens!) is more likely to cause frustration than a sense of release (Golembiewski, 2013d).) The same goes for inaccessible views of nature through impenetrable walls. But the quality of finish and construction on the other hand cannot be easily dismissed. There is no doubt that culturally some styles will fit better than others, especially in the domestic milieu, but quality transcends these differences because it says, 'we care about you' even beyond the mannerisms of style. Natural environments that are so cherished by advocates of ART, SRT and the BH serve a key role here. Good views generally are salutogenic, and more so if they reinforce our place as part of something bigger than ourselves like the natural environment. This effect is enormous. In a German city, people were cued to rate their subjective experience about 10 times/day over a week on a phone app. When asked, they rated subjective measures of wellness and happiness. This data was correlated to a map showing where the participants were, and how much greenery (a generic positive aesthetic affordance) was around them when they gave their ratings. Results showed that even a little greenery positively and robustly impacted on all health and happiness measures (Tost et al., 2019). The study was replicated with a neuroimaging study and a twist: Visible urban greenery made people feel on average 9-10 points better (on a 0-100 visual analogue scale), even when the subject was also exposed to salient emotionally aversive cues. Meanwhile, the greenery caused a significant deactivation of the dorsolateral prefrontal cortex (DLPFC) during this negative exposure, suggesting that negative social affordances were cancelled out by the green aesthetic experience. This makes sense - at least in as much as people care about the environment (and the recent wave of interest that catapulted Greta Thunberg to fame suggests that the green issue is more important to many people than religion.) And if there is validity in the ART, SRT and BH, then to at least a lesser extent, in everyone else also. So buildings that look out into nature or make an effort to reduce the carbon footprint (Fig. 26.8) naturally make people feel they are doing something meaningful for the environment and therefore improve meaningfulness.

\section{Providing for Meaningful Engagement}

Meaningfulness in architecture is improved whenever the design enables engagement in the things that create meaning and joy. The things we engage in are personal, and for this reason, meaningfulness is a shifting goalpost, changing with life-experience and circumstance. But humans are fundamentally alike. Humanity is at shared at familial, cultural, societal and even universal levels. If we consider the places people find meaning at these levels, then we can design spaces that afford those activities (without detracting from them) (Table 26.1).

\section{Design for Positive Choices}

Providing opportunities for engagement makes for good salutogenic interventions. But better still, is a choice of good things to get engaged in. A sense of abundance removes the pressures of poverty to make way for a sense of happiness (Cook, 2017), and there is no better way to impress a sense of abundance on people that by providing irresistible, positive choices. Over the history of mankind - or even of life itself, people have had few opportunities to sit back and make such choices, tethered as we tend to be by the demands of daily life whether it be filing tax returns to escape an audit from tax department trolls, or tilling fields to make sure there's stock for winter. If this sense of abundance and quality can be anchored by the architecture, there is little left for the architecture to do to create meaning. But the individual needs that are at the heart of meaningfulness are more important than choices alone: 'positive choices' do not always mean decadent indulgence - to some individuals the best choice may be to just 'be'. There is a salutary lesson in the myth of Prince Siddhartha, who rejected the trappings of the palace to sit naked under a mango tree to become the enlightened Buddha. Just as manageability sometimes needs to be sacrificed for comprehensibility of meaningfulness, so too the trappings of meaningfulness may need to be sacrificed for the thing itself - but that is no longer the domain of architecture.

\section{Discussion}

Since Dilani (2006) brought the concept of salutogenesis to healthcare design, he has led the International Academy for Design and Health to promote salutogenic theory in healthcare architecture throughout the world, even offering an annual prize for excellence in salutogenic architecture. As 


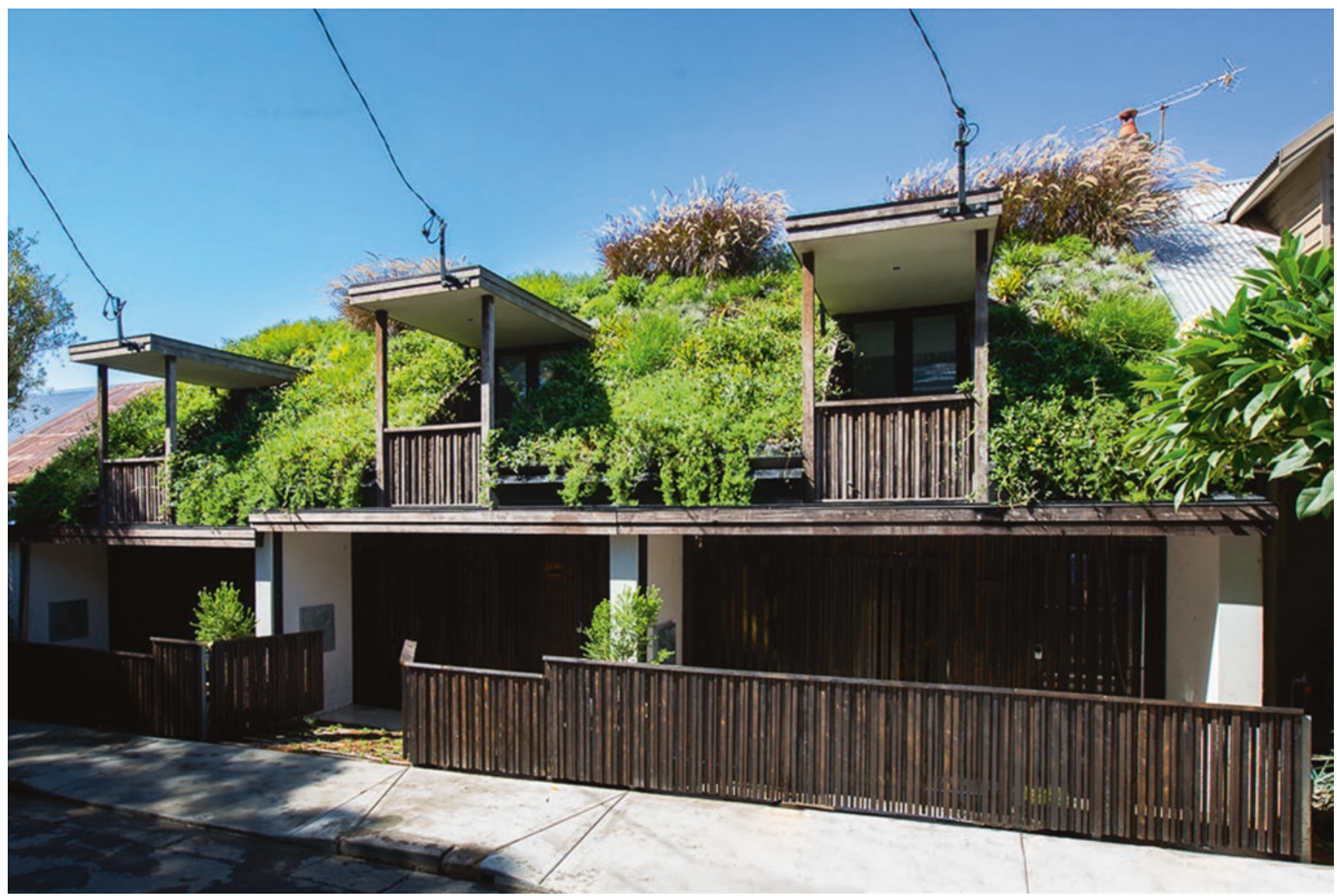

Fig. 26.8 88 Angel, by Steele Associates Architects, is a stage-set that makes a clear statement about meaningfulness. This terrace of lowenergy houses not only provides 'views of nature' it is buried by it and it also gives views away to neighbours and passers-by. It is also located near the heart of Sydney so it is the perfect place to establish social connections. (Photograph (C) Steele Associates Architects, courtesy of Steele Associates Architects)
Table 26.1 Some generic architectural solutions to encourage the discovery and maintenance of meaning in life

\begin{tabular}{l|l}
\hline $\begin{array}{l}\text { Area of } \\
\text { engagement }\end{array}$ & Practical solutions \\
\hline $\begin{array}{l}\text { Interests: } \\
\text { intellectual } \\
\text { works, sports. }\end{array}$ & $\begin{array}{l}\text { Studios, halls rooms and spaces designed for } \\
\text { specific activities (that do not detract by being } \\
\text { too noisy/too quiet, too difficult to keep clean } \\
\text { etc. See manageability). }\end{array}$ \\
\hline Animals & $\begin{array}{l}\text { Design for pets. Is there sufficient space? Are } \\
\text { there open areas? Are the surfaces going to } \\
\text { limit the inconvenience of fur, feathers, poo } \\
\text { and animal noises? }\end{array}$ \\
\hline $\begin{array}{l}\text { Family and } \\
\text { friends }\end{array}$ & $\begin{array}{l}\text { Good spaces for entertaining. Fun provisions } \\
\text { for visitors (got a swimming pool?) Kitchens } \\
\text { that are in the heart of the action, spaces for } \\
\text { kids to play safely, etc.. }\end{array}$ \\
\hline Greater society & $\begin{array}{l}\text { Good locations, urban living, good transport } \\
\text { connections, appropriate typologies and } \\
\text { decorous designs. }\end{array}$ \\
\hline World & $\begin{array}{l}\text { Views of nature, natural materials, low-carbon } \\
\text { footprint. }\end{array}$ \\
\hline Universe & $\begin{array}{l}\text { Bespoke religious affordances and symbols, } \\
\text { 'sacred' architectural forms. }\end{array}$ \\
\hline
\end{tabular}

a result, the concept has grown in popularity at least as a buzzword. The result is that salutogenesis is now a respected and encouraged design goal. The downside is that the term 'salutogenic' is overused by architects, most of whom do not know what it means. As a result, at times, the term can mean nothing more systematic than 'friendly-looking' or 'leafy'. This is not to criticise those designs - after all, 'nice looking' and 'leafy' are often the outcomes of more systematic salutogenic approaches, but there is so much more unexplored potential in the concept. There are now systematic methods to bring salutogenic principles in many areas of institutional design: healthcare design (Golembiewski, 2010, 2015) and emergency care (Golembiewski, 2012b) and aged care (Golembiewski, 2017a, 2017b) and dementia care (Chap. 48 of this volume). And when adopted appropriately, salutogenic architecture is invariably exemplary. Some of these projects reach beyond the accepted evidence basis for health-promoting design (generic factors like views of nature and allowances for natural daylight) and explore the realms of story-making, psychology, neuroscience and 
endocrinology. It is now time for salutogenesis in design to be deployed outside of institutions, in workplaces, in urban designs and in people's own homes. But for this to happen, it is time to wrestle the term from the clutches of marketeers, and for solid salutogenic theory to become part of the architects' tool-bag.

\section{Challenges for the Future}

Salutogenic principles are a practical way to integrate the dynamics of health and experience with architecture. But for people in praxis, challenges abound: in most countries the procurement systems are conservative, and led by precedents and guidelines, and controlled by stakeholder groups who struggle to save capital, often with little regard for on-going healthcare costs. The decision-makers are usually poorly informed or simply do not believe in the capacity of aesthetics to influence health. To add to this, the pathogenic model of health is dominant in the healthcare sector, a field with enormous inertia, which will not reorient towards health promotion easily. As a result, stakeholders may place a greater stake in 'keeping it normal' than on real benefits of change. Belief in the value of functional efficiencies, traditional finishes and approaches are not changing fast. Although some groups (particularly in the private sector) are beginning to understand how salutogenic values can lift their game when faced with shrinking budgets, tight deadlines, constricted sites and profit-oriented project managers, the question is will they have the courage to go beyond generic 'views of nature' tropes?

\section{References}

Albright, R. (2015). Neuroscience for architecture. In S. Robinson \& J. Pallasmaa (Eds.), Mind in architecture: Neuroscience, embodiment and the future of design (pp. 197-219). MIT Press.

Antonovsky, A. (1972). Breakdown: A needed fourth step in the conceptual armamentarium of modern medicine. Social Science \& Medicine, 6(5), 537-544.

Antonovsky, A. (1979). Health, stress, and coping. Jossey-Bass.

Antonovsky, A. (1987). Unravelling the mystery of health: How people manage stress and stay well. Jossey-Bass.

Antonovsky, A. (1996). The salutogenic model as a theory to guide health promotion. Health Promotion International, 11(1), 11.

Bargh, J. A. (1994). The four horsemen of automaticity: Awareness, intention, efficiency, and control in social cognition. Handbook of social cognition: Basic processes, 1, 1ñ40.

Beauchemin, K. M., \& Hays, P. (1996). Sunny hospital rooms expedite recovery from severe and refractory depressions. Journal of Affective Disorders, 40, 49-51.

Beauchemin, K. M., \& Hays, P. (1998). Dying in the dark: Sunshine, gender and outcomes in myocardial infarction. Journal of the Royal Society of Medicine, 91, 352-354.
Berns, G. S., Chappelow, J., Cekic, M., Zink, C. F., Pagnoni, G., \& Martin-Skurski, M. E. (2006). Neurobiological substrates of dread. Science, 312(5774), 754-758. https://doi.org/10.1126/ science. 1123721

Brager, G. S., \& de Dear, R. J. (1998). Thermal adaptation in the built environment: A literature review. Energy and Buildings, 27(1), 83-96. Retrieved from http://www.sciencedirect.com/science/ article/B6V2V-3SYXHRY-9/2/4d52df91215e9c9e0401d0cfb21da $59 \mathrm{~b}$

Browning, R. (1856). Andrea Del Sarto. In Men And Women. Ticknor and Fields.

Calhoun, J. (1952). The social aspects of population dynamics. Journal of Mammalogy, 139-159.

City of New York. (2013). Active design: Shaping the sidewalk experience. NYC.

Clarkson, J., Coleman, R., Keates, S., \& Lebbon, C. (2003). Inclusive Design: Design for the whole population. In: J. Clarkson, R. Coleman, S. Keates, \& C. Lebbon (Eds.).

Cook, D. (2017). The ART of Hope: Healing the Wounded City. In R. Phillips \& C. Wong (Eds.), Handbook of community well-being research (pp. 39-68). Springer Nature.

Cooke, J. (2001). Architects, engineers and the law (3rd ed.). Federation Press.

Deguchi, T., \& Axelrod, J. (1972). Control of circadian change of serotonin $\mathrm{N}$-acetyltransferase activity in the pineal organ by the ß-Adrenergic receptor. PNAS, 69(9), 2547-2550.

Dijkstra, K., Pieterse, M., \& Pruyn, A. (2006). Physical environmental stimuli that turn healthcare facilities into healing environments through psychologically mediated effects: A systematic review. Journal of Advanced Nursing, 56(2), 166-181. https://doi. org/10.1111/j.1365-2648.2006.03990.x

Dilani, A. (2006). A new paradigm of design and health in hospital planning. World Hospitals and Health Services, 41(4), 17-21.

Dilani, A. (2008). Psychosocially supportive design: A salutogenic approach to the design of the physical environment. Design and Health Scientific Review, 1(2), 47-55.

Frankl, V. E. (1963). Man's search for meaning: An introduction to Logotherapy. Pocket Books.

Gibson, J. J. (1979). The ecological approach to visual perception. Houghton Mifflin Company.

Golembiewski, J. (2010). Start making sense; applying a salutogenic model to architectural design for psychiatric care. Facilities, 28(3/4), 100-117. https://doi.org/10.1108/02632771011023096

Golembiewski, J. (2012a). All common psychotic symptoms can be explained by the theory of ecological perception. Medical Hypotheses, 78, 7-10. https://doi.org/10.1016/j.mehy.2011.09.029

Golembiewski, J. (2012b). Moving from theory to praxis on the fly; introducing a salutogenic method to expedite mental healthcare provision. Australian Journal of Emergency Management, 27(1), 42-47. Retrieved from http://www.em.gov.au/Publications/ Australianjournalofemergencymanagement/Pastissues/Pages/ AJEM27TWO/Moving-from-theory-to-praxis-on-the-flyintroducing-a-salutogenic-method-to-expedite-mental-health-careprovision-in-disas.aspx

Golembiewski, J. (2012c). Salutogenic design: The neural basis for health promoting environments. World Health Design Scientific Review, 5(4), 62-68.

Golembiewski, J. (2013a). Are diverse factors proxies for architectural influences? A case for architecture in the aetiology of schizophrenia. Curēus, 5(3), e106. https://doi.org/10.7759/cureus.106

Golembiewski, J. (2013b). Determinism and desire: Some neurological processes in perceiving the design object. International Journal of Design in Society, 6(3), 23-36. 
Golembiewski, J. (2013c). Lost in space: The role of the environment in the aetiology of schizophrenia. Facilities, 31(9/10), 427-448.

Golembiewski, J. (2014). Introducing the concept of reflexive and automatic violence: a function of aberrant perceptual inhibition. Archives of Psychiatry and Psychotherapy, 16(4), 5-13. https://doi. org/10.12740/app/33358

Golembiewski, J. (2015). Salutogenic architecture in health care settings. In G. Bauer \& M. Mittelmark (Eds.), Handbook of Salutogenesis: Past, present and future (pp. 267-276). Springer Nature.

Golembiewski, J. (2016). The designed environment and how it affects brain morphology and mental health. HERD, 9(2), 161-171. https:// doi.org/10.1177/1937586715609562

Golembiewski, J. (Writer). (2017a). Salutogenic approaches for dementia care. In Dementia Training Australia Training Webinars. Dementia Training Australia.

Golembiewski, J. (Producer). (2017b, 12/12/2017). Salutogenics for Dementia Care. Dementia Training Australia. [Webinar] Retrieved from https://www.youtube.com/watch? $\mathrm{v}=5 \mathrm{v} \_$UOakjUoI

Harari, Y. N. (2015). Sapiens: A brief history of humankind. HarperCollins

Ittelson, W. H. (1978). Environmental perception and urban experience. Environment and Behavior, 10(2), 193.

Jackson, R., \& Sinclair, S. (2012). Designing healthy communities. Jossey-Bass.

Kaplan, R., \& Kaplan, S. (1989). The experience of nature: A psychological perspective. Cambridge University Press.

Kaplan, S., \& Kaplan, R. (1982). Cognition and environment. Praeger.

Keinan, G. (1994). The effects of stress and tolerance of ambiguity on magical thinking. Journal of Personality and Social Psychology, 67(1), 48-55.

Kruglanski, A. W., Chen, X., Dechesne, M., Fishman, S., \& Orehek, E. (2009). Fully committed: Suicide Bombers' motivation and the quest for personal significance. Political Psychology, 30(3), 331-357.

Lawton, M. P., \& Nahemow, L. (1973). Ecology and the aging process. In C. Eisdorfer \& M. Powell Lawton (Eds.), Social environment of aging (pp. 619-673). American Psychological Association.

Le Hunte, B., \& Golembiewski, J. (2014). Stories have the power to save us: A neurological framework for the imperative to tell stories. Arts and Social Sciences Journal, 5(2), 73-77. https://doi. org/10.4172/2151-6200.1000073

Libman, K., Fields, D., \& Saegert, S. (2012). Housing and health: A social ecological perspective on the US foreclosure crisis. Housing, Theory and Society, 29(1), 1-24. https://doi.org/10.1080/14036096 .2012 .624881

Maslow, A. H. (1962). Lessons from the peak-experiences. Journal of Humanistic Psychology, 2(1), 9-18. https://doi. org/10.1177/002216786200200102

Mason, O., Startup, M., Halpin, S., Schall, U., Conrad, A., \& Carr, V. (2004). Risk factors for transition to first episode psychosis among individuals with 'at-risk mental states'. Schizophrenia Research, 71(2-3), 227-237. https://doi.org/10.1016/j.schres.2004.04.006
Mazuch, R. (2017). Salutogenic and Biophilic design as therapeutic approaches to sustainable architecture. Architectural Design.

Mittelmark, M. B., \& Bull, T. (2013). The salutogenic model of health in health promotion research. Global Health Promotion, 20(2), 30-38. https://doi.org/10.1177/1757975913486684

Mittelmark, M. B., Bull, T., Daniel, M., \& Urke, H. (2017). Specific resistance resources in the salutogenic model of health. In M. B. Mittelmark, S. Sagy, M. Eriksson, G. F. Bauer, J. M. Pelikan, B. Lindström, \& G. A. Espnes (Eds.), The handbook of Salutogenesis (pp. 71-76). Springer.

Rubenstein, J. L. (1994). The symbolism of the sukkah. Judaism, 43(4), 371.

Sapolsky, R. (2004). Why zebras Don't get ulcers: An updated guide to stress, stress related diseases, and coping (3rd ed.). Henry Holt and Company.

Sapolsky, R. M. (2017). Behave: The biology of humans at our best and worst. Penguin Press.

Searles, H. F. (1960). The non-human environment in normal development and in schizophrenia. International Universities Press.

Searles, H. F. (1966). Concerning the development of an identity. Psychoanalytic Review, 53(4), 7-30. Retrieved from http://www. pep-web.org

Strümpfer, D., Gouws, J., \& Viviers, M. (1998a). Antonovsky's sense of coherence scale related to negative and positive affectivity. European Journal of Personality, 12(6), 457-480.

Strümpfer, D., Gouws, J., \& Viviers, M. (1998b). Item phrasing in Antonovsky's sense of coherence scale related to negative and positive affectivity. Personality and Individual Differences, 24(5), 669-675.

Tost, H., Reichert, M., Braun, U., Reinhard, I., Peters, R., Lautenbach, S., ... Meyer-Lindenberg, A. (2019). Neural correlates of individual differences in affective benefit of real-life urban green space exposure. Nature Neuroscience. https://doi.org/10.1038/ s41593-019-0451-y

Turley, L. W., \& Milliman, R. E. (2000). Atmospheric effects on shopping behavior: A review of the experimental evidence. Journal of Business Research, 49(2), 193-211.

Ulrich, R. S. (1991). The Effects of Interior Design on Wellness; Theory and Recent Scientific Research. Paper presented at the Journal of Health Care Interior Design; Proceedings from the National Symposium on Health Care Interior Design.

Vincent, N. C. (2012). Shaker Furniture. Heilbrunn Timeline of Art History. Retrieved from http://www.metmuseum.org/toah/hd/shak/ hd_shak.htm

Wilson, E. O. (1984). Biophilia: The human bond with other species. Harvard University Press.

Woodbury, M., \& Woodbury, M. (1969). Community centered psychiatric intervention: A pilot project in the 13th arrondissement, Paris. American Journal of Psychiatry, 126(5), 619-625.

Zook, J. B., \& Ewing, R. (2010). Active design guidelines: promoting physical activity and health in design. Retrieved from New York:

Open Access This chapter is licensed under the terms of the Creative Commons Attribution 4.0 International License (http://creativecommons. org/licenses/by/4.0/), which permits use, sharing, adaptation, distribution and reproduction in any medium or format, as long as you give appropriate credit to the original author(s) and the source, provide a link to the Creative Commons license and indicate if changes were made.

The images or other third party material in this chapter are included in the chapter's Creative Commons license, unless indicated otherwise in a credit line to the material. If material is not included in the chapter's Creative Commons license and your intended use is not permitted by statutory regulation or exceeds the permitted use, you will need to obtain permission directly from the copyright holder. 